\title{
ANÁLISE DA PERCEPÇÃO DA COMUNIDADE LOCAL E DA PARTICIPAÇÃO POPULAR NO PROCESSO DE CRIAÇÃO DE UNIDADES DE CONSERVAÇÃO
}

\author{
Roberto Rochadelli*, Anadalvo Juazeiro dos Santos*, Luane Isabel Dias Milder**, \\ Alessandro Vinícios Schneider*** \\ *Eng. Florestal, Dr., Departamento de Economia Rural e Extensão, UFPR - nashtell@ufpr.br - ajsantos@ufpr.br
**Eng. Florestal, M.Sc.- luanemilder@ig.com.br \\ ***Administrador, M.Sc., UNIMEO/CTESOP - schneideravs@ig.com.br
}

Recebido para publicação: 28/06/2005 - Aceito para publicação: 28/03/2008

\begin{abstract}
Resumo
A implantação e gerenciamento de Unidades de Conservação são exigências da recente Lei Federal 9985/00 - Lei do Sistema Nacional de Unidades de Conservação. Tal medida prevê consulta pública precedente à criação da unidade e obrigatoriedade de fornecimento de informações adequadas e inteligíveis à população local e outros interessados. A Área de Proteção Ambiental do Rio Verde, Região Metropolitana de Curitiba, estado do Paraná, Brasil, é uma das pioneiras no estado a implantar o processo de participação popular. Analisar esse processo foi o objetivo do presente trabalho. A metodologia aplicada foi a análise dos transcritos das reuniões públicas, a aplicação de questionários à população rural da área e entrevistas com técnicos que participaram do processo. A conclusão a que se chegou foi que as reuniões públicas foram efetivas para informar aspectos contextuais, mas deficientes em elucidar termos técnicos e em dialogar com a população local sobre pontos polêmicos ou conflitantes.

Palavras-chave: Consulta pública; unidades de conservação; desenvolvimento sustentável.
\end{abstract}

\section{Abstract}

Analysis of local community perceptions and the popular participation in the creation of protected areas. The implementation and management of this areas is a requirement of the federal law 9985/00 - Law of the National System of Conservation Units. Such requirement foresees popular consulting preceding the creation of the unit and the obligation of supplying the population and other interested parties with intelligible information. The Environment Protection Area of Rio Verde, which is in the Curitiba Metropolitan Area, Paraná State, Brazil, is one of the pioneers in the state to implement this popular participation process. To analyze this process is the objective of this paper. The used methodology was transcription analysis of public meetings, survey made among the agricultural population and interviews with technicians who took part in the process. The results have shown that the meetings of the popular participation was effective for information about the context, but deficient for clarifying technical terms and for communicating with the population about controversial points. Keywords: Public consulting; protected areas; sustainable development.

\section{INTRODUÇÃO}

A participação popular nos processos de planejamento é uma conquista proporcionada pela Carta Magna de 1988. Alguns estados e municípios, lançando mão desse poderoso instrumento democrático, passaram a praticar o orçamento participativo, além do que a participação popular é obrigatória para se estabelecer o plano de uso do solo nas cidades. A Lei Federal 9985, de 18 de julho de 2000 (Lei do Sistema Nacional de Unidades de Conservação), exige a participação popular na criação, implantação e gerenciamento de unidades de conservação. Tal exigência prevê estudos técnicos e consulta pública precedente à criação da unidade e obrigatoriedade de fornecimento de informações adequadas e inteligíveis à população local e outros interessados, por parte do poder público. 
Diversas instituições estiveram envolvidas na elaboração do macrozoneamento econômicoecológico da Área de Proteção Ambiental do Rio Verde: Coordenação da Região Metropolitana de Curitiba (COMEC), Instituto Ambiental do Paraná (IAP), Companhia de Saneamento do Paraná (SANEPAR), Empresa de Assistência Técnica e Extensão Rural do Paraná (EMATER), Minerais do Paraná (MINEROPAR), Superintendência de Recursos Hídricos e Saneamento Ambiental (SUDERHSA) e Petróleo do Brasil (PETROBRÁS).

Os levantamentos preliminares foram iniciados em abril de 2002, por empresa consultora contratada pela COMEC. O processo de participação popular para implementação do Macrozoneamento Ecológico-Econômico da APA do Rio Verde contou com 5 reuniões informais com a sociedade civil, organizadas a fim de viabilizar o levantamento de dados e, principalmente, visando ao preparo e capacitação no processo do planejamento da APA e das audiências públicas. As reuniões foram realizadas entre agosto e setembro de 2002, nas colônias de Figueiredo, Timbotuva, Rebouças e Rondinha, no município de Campo Largo, e Colônia Cristina, no município de Araucária. Nessas reuniões, foi aplicado um questionário para coleta de informações que subsidiassem os trabalhos de elaboração do macrozoneamento.

A metodologia empregada para a coleta de dados em campo pela equipe técnica que elaborou o macrozoneamento considerou realizar, antes das saídas a campo, uma palestra de sensibilização junto às lideranças da comunidade, para disseminação (externa) da pesquisa, que seria então realizada na região. As entrevistas junto à comunidade foram previstas para serem realizadas durante 6 semanas, entre os meses de abril e maio/02. A palestra de sensibilização não foi realizada. A equipe que realizou os trabalhos de campo foi coordenada por um economista e um sociólogo.

As reuniões públicas foram programadas de modo a se fazer uma única reunião com entidades envolvidas no processo e representantes da comunidade. A reunião com as instituições ocorreu em 30/08/02, mas na ata da reunião não há assinatura de nenhum representante dos moradores da APA, ou seja, as instituições nunca se reuniram com a comunidade. As reuniões contaram com uma explanação por parte dos coordenadores do processo, com uso de imagens projetadas, a apresentação dos parâmetros levantados sobre a região, a definição de termos, a apresentação de leis, etc., a abertura para questionamentos e sugestões (que foram colhidos de forma verbal e escrita) e aplicação de questionário escrito, preenchido pela população presente.

A Audiência Pública foi realizada no dia 29 de outubro de 2003, no Ginásio do Polentão, em Campo Largo, no km 114 da BR 277, exatamente um ano após a data primeiramente estabelecida, que seria outubro de 2002. Tal atraso foi devido a pressões populares e do governo dos municípios envolvidos, descontentes com alguns aspectos do macrozoneamento, o que adiou a audiência até a troca do governo estadual e mudanças internas na COMEC. Essa pausa significativa de um ano poderia ser uma forma de amenizar as animosidades da comunidade em relação à APA, porém observou-se que isso não aconteceu. A população preservou as fortes impressões causadas pelas reuniões populares, o que levou a manifestações acaloradas na audiência pública, inclusive o pedido de cancelamento dias antes de sua realização.

Todo o diagnóstico e o processo de construção participativa estão registrados em extenso volume de informações nas bibliotecas do IAP e da COMEC, à disposição para consulta pública. De todas as APA's do Paraná, a do Rio Verde é a que possui maior volume de informações, em função do processo de participação popular. As reuniões públicas foram todas gravadas e transcritas. Os questionários, convites e cartazes foram todos fotocopiados e anexados aos registros. O diagnóstico da região está detalhado, bem como o plano de trabalho. Existe uma fonte de consulta riquíssima para futuros processos semelhantes e também para pesquisas, trabalhos e elaboração de políticas públicas.

O presente trabalho teve como objetivo analisar a percepção da comunidade local e da participação popular no processo da criação da unidade de conservação da APA do Rio Verde, no Estado do Paraná.

\section{REVISÃO BIBLIOGRÁFICA}

"A democracia, que parece se firmar nesse século, assegura ao indivíduo a possibilidade de se formar sujeito e, por isso, ela não é simplesmente outorgada por uma constituição de um regime político; mas sim obtida através do esforço e de uma vivência que passa a ser assimilada enquanto cultura" (BRANDENBURG, 1999). 
Quando Brandenburg refere-se a "sujeito", está se referindo a uma figura que, nas últimas décadas, esteve ausente nas análises da sociologia, e que reaparece "como fruto de resistência aos poderes autoritários de nosso século [...] e recoloca a análise no centro de uma sociedade, que embora massificada e cada vez mais globalizada, procura resgatar valores culturais tidos como impeditivos do processo de modernização social".

Esse sujeito que está sendo construído, assegurado pela democracia frágil e emergente, é o objeto central das participações populares nos processos de decisão. A causa ambiental, através das suas características peculiares, que exigem o gerenciamento comum dos recursos, propicia a afirmação desse sujeito. "A participação é o próprio processo de criação do homem ao pensar e agir sobre os desafios da natureza e sobre os desafios sociais, nos quais ele próprio está situado" (SOUZA, 1987).

"Um cidadão que tem a oportunidade de participar do processo elaborativo da decisão, e que não é afrontado pela administração com o fato consumado, tem grande boa vontade para aceitar e acomodarse à decisão. De outro lado, a participação pública no processo elaborativo da decisão pode reduzir muito o potencial de conflito, que de outra forma existiria, desde que a participação do público tenha sido efetiva e em tempo oportuno" (GÜNDING, 1980).

A consulta pública aparece como um instrumento de prática democrática e, por conseguinte, de construção do sujeito. A ação é uma das facetas da formação do indivíduo como sujeito e este "se afirma à medida que se reproduz enquanto produtor de uma situação e não, simplesmente, como um produto social" (BRANDENBURG, 1999). A consulta pública pressupõe ação, mas não se pode esperar que essa "sociedade massificada" aja de imediato. Há um processo a ser seguido, do qual não se podem pular etapas. Segundo o autor, "na sua trajetória, o movimento social passa de contestador, ou de reivindicador, a realizador de um projeto. Chega-se, então, no seu estágio de maturidade quando passa do discurso para o campo da formulação e da execução de propostas. Esta fase exige um maior engajamento e responsabilidade do sujeito, principalmente da liderança que se encontra na direção do movimento".

Em processos de participação popular, relacionados à questão ambiental, diferentemente de outros processos de consulta pública, a gestão ambiental "mobiliza a participação da população na tomada de decisões que afetam as suas condições de existência, desencadeando a energia e a criatividade social para gerar uma nova cultura política, e múltiplas opções de organização produtiva” (LEFF, 2000). "Se uma população apenas produz e não usufrui dessa produção, ou se ela produz e usufrui, mas não toma parte na gestão, não se pode afirmar que ela participe verdadeiramente" (BORDENAVE, 1983). Portanto, tais processos de gestão ambiental são boas oportunidades de se obter da população a contribuição necessária de forma adequada.

Souza (1987) explica que o profissional que deseja ampliar as condições sociais da participação deve, em conjunto com a população, através de processos contínuos de discussões e debates, descobrir os enfrentamentos específicos requeridos por cada realidade de participação a ser trabalhada. "A descoberta dos interesses da população é, por conseguinte, o primeiro elemento a ser trabalhado nas relações com a população". Segundo o autor, o profissional tecnocrata que se aproxima da população através de seu universo tecnocrata, não respeitando os limites de vivência da população, não propicia um ambiente propício para a participação.

Dietz; Tamaio (2000) sugerem que as "pessoas irão atuar nos problemas que sejam relevantes para elas. Há uma conexão forte entre emoção e motivação. Por isso, todos os processos de educação e desenvolvimento devem começar identificando as situações que a população local comenta com entusiasmo, esperança, medo, ansiedade ou raiva nas praças, bares, igrejas e centros comunitários".

“A participação supõe um processo contínuo de capacitação da população" (Souza, 1987). E a capacitação, como processo pedagógico, supõe que se devam proporcionar à população estimulação e assessoramento que forneçam meios de apreensão contínua da realidade social e capacidade de analisálas, além de instrumentalização para os projetos e pesquisas que reforcem suas reivindicações, desenvolvam sua comunicação com os diversos grupos sociais e promovam o conhecimento de leis e políticas que lhes dizem respeito.

A participação tende para a organização e a organização facilita e canaliza a participação (BORDENAVE, 1983). Com efeito, as comunidades organizadas têm mais facilidade para encontrar os canais de participação. O contrário também é verdadeiro, isto é, pessoas que não fazem parte de uma organização social encontram mais dificuldade para se expressar, seja pela falta de prática, seja pela falta de confiança. "Em um grupo democrático é importante repartir a liderança, tomar decisões em grupo e 
criar consenso. Esses elementos necessitam de tempo, confiança e sinceridade" (DIETZ; TAMAIO, 2000).

De fato, a participação depende de "uma vivência coletiva, não individual, de modo que somente se pode aprender na práxis grupal” (BORDENAVE, 1983). Pessoas organizadas socialmente, e que já praticam a participação em um determinado nível, tendem a estar mais preparadas para participar em outras instâncias, pois só se aprende participando (MILDER, 2004).

A efetiva participação na tomada de decisões requer pelo menos dois processos comunicativos: a informação e o diálogo.

A participação democrática se baseia em canais institucionais. Em primeiro lugar, de informação: não há participação popular sem informação qualitativamente pertinente e quantitativamente abundante sobre os problemas, os planos e os recursos públicos. Em segundo lugar, canais de consulta. Em terceiro lugar, canais de reivindicação e de protesto. [...] A participação democrática começa quando os grupos da população interessada em um tema específico recebem informação específica, conhecem os canais de reivindicações e são alertados para as formas de consulta a que têm acesso. Um governo democrático aberto à participação é aquele que informa corretamente, ouve cuidadosamente e consulta ativamente a população (BORDENAVE, 1983).

“Arriscar a participar na formação de uma decisão, ou em lidar abertamente com o conflito e comportamento emocional do grupo, requer coragem e responsabilidade. $\mathrm{O}$ medo de explorar ou experimentar pode resultar em reuniões ineficientes e sem sentido" (DIETZ; TAMAIO, 2000).

\section{MATERIAL E MÉTODOS}

O estudo foi desenvolvido na Área de Proteção Ambiental Estadual do Rio Verde, doravante referida apenas como $A P A$ ou $A P A$ do Rio Verde. Essa Unidade de Conservação está inserida na área dos municípios de Campo Largo e Araucária, que fazem parte da Região Metropolitana de Curitiba (RMC), a uma média de $30 \mathrm{~km}$ a oeste de Curitiba. Criada pelo decreto estadual $\mathrm{n}^{\mathrm{o}} 2375$, de 31 de julho de 2000, tem como objetivo proteger e conservar a qualidade ambiental e dos sistemas naturais, em especial a qualidade e quantidade da água para fins de abastecimento público. A APA possui uma área de $146 \mathrm{~km}^{2}$ (ou $14.600 \mathrm{ha}$ ), abrigando áreas urbanas e rurais. $\mathrm{Na}$ área rural há 259 propriedades, segundo o Macrozoneamento Ecológico-Econômico da APA Estadual do Rio Verde (Produto 08A - Volume I/IV, Outubro, 2002).

O município de Campo Largo ocupa 72,8\% da área da APA e Araucária 27,2\%. No entanto, 8,21\% e 8,14\% das áreas de Campo Largo e de Araucária, respectivamente, estão inseridas na APA, (Tabela 1). Campo Magro abriga as nascentes do rio, mas não foi contemplado pelo macrozoneamento, pois seu território já conta com zoneamento anterior, uma Unidade Territorial de Planejamento (UTP), que não é uma unidade de conservação, mas impõe também restrições ao uso do solo.

Tabela 1. Área dos municípios integrantes da bacia contribuinte à Represa do Rio Verde.

Table 1. Area of de integrated municipalities of the feed waters for the Rio Verde Dam.

\begin{tabular}{lccc}
\hline Município & $\begin{array}{c}\text { Área total do município } \\
\left(\mathbf{k m}^{\mathbf{2}}\right)\end{array}$ & $\begin{array}{c}\text { Área inserida na bacia } \\
\left(\mathbf{k m}^{\mathbf{2}}\right)\end{array}$ & $\begin{array}{c}\text { Área inserida na APA } \\
\left(\mathbf{k m}^{\mathbf{2}} \mathbf{)}\right.\end{array}$ \\
\hline Araucária & 473,85 & 38,95 & 38,95 \\
Campo Largo & 1326,39 & 107,98 & 107,98 \\
Campo Magro & 262,49 & 18,40 & --- \\
\hline
\end{tabular}

Macrozoneamento Ecológico-Econômico da APA do Rio Verde - Produto 4.

Os municípios que integram a bacia contribuinte à Represa do Rio Verde possuem uma taxa média de crescimento populacional igual a 4,55\% ao ano, superior à média da RMC, que indicou no mesmo período comparativo (1996-2000) uma taxa de 3,17\% ao ano, e superior também à média do Estado, que é de $1,5 \%$ ao ano. Através do uso dos mapas contidos no diagnóstico para o macrozoneamento, foram identificadas 12 grandes comunidades que compõem a APA, chamadas colônias, muito próximas umas das outras, sendo seus limites definidos apenas por informações verbais dos moradores e, muito raramente, por placas de sinalização. Destas, 9 foram objetos deste estudo, a saber: Colônia Timbotuva, Colônia Antônio 
Rebouças, Colônia Rio Verde Faxinal do Tanque, Colônia Cristina, Colônia Mariana, Colônia Rondinha, Colônia Fazendinha, Colônia Figueiredo e Colônia Ferraria.

A população, na sua maior parte, é formada por agricultores familiares, descendentes, na sua grande maioria, de poloneses, e em proporções bem menores, de italianos, que chegaram à região há mais de cem anos e que plantam, sobretudo, milho, feijão, cebola e verduras. Em menor escala estão trigo, soja, morango e pêssego e plantas medicinais, como calêndula e camomila. O cultivo de batata já foi amplamente utilizado.

As informações para o presente trabalho foram coletadas através de questionários aplicados in situ a moradores da zona rural e através de entrevistas com técnicos responsáveis pela elaboração do macrozoneamento. Os questionários apresentaram questões estruturadas entremeadas por questões abertas, de acordo com a natureza da pergunta. Comentários e observações dos entrevistados, não previstos no questionário, foram considerados e anotados. Os questionários foram aplicados em campo, dirigidos a moradores da zona rural, de acordo com sua linguagem própria, com o intuito de medir dois processos comunicativos: o de informação e o de diálogo (BORDENAVE, 1983e). Para tanto, o questionário abrangeu perguntas de três tipos: perguntas de constatação, perguntas de opinião e perguntas-filtro.

As perguntas de constatação, do tipo “O(a) senhor(a) já ouviu falar em APA?” ou “O(a) senhor(a) tem conhecimento de que mora numa área de proteção ambiental ou APA?”, assumiram respostas objetivas, como: sim, não, não sei. Seu objetivo foi constatar o grau de informação passado à população sobre o tema da participação popular. As perguntas de opinião, do tipo "A reunião foi esclarecedora para o(a) senhor(a)?", assumiram como resposta alternativas que permitiram a percepção do grau de diálogo estabelecido no processo de participação. Denominaram-se perguntas-filtro aquelas que serviram justamente para filtrar as perguntas de opinião, ou seja, classificaram a população em categorias socioeconômicas, com o intuito de comparar suas opiniões. Tais perguntas foram: idade, sexo, escolaridade, tamanho da propriedade, tipo de renda, tempo que a propriedade pertence à família, se recebe assistência técnica e se pertence a alguma entidade de classe.

As propriedades foram escolhidas ao acaso e considerando alguns preceitos estatísticos citados por Draper (1981): amostrar pelo menos $75 \%$ das colônias identificadas e $20 \%$ das propriedades rurais e ter representatividade de cada colônia com pelo menos $11 \%$ ( $\pm 5 \%$ ). Isso significa dizer que, das 259 propriedades rurais da APA, ao menos 52 deveriam ser entrevistadas, e das 12 colônias, 9 deveriam estar representadas com no mínimo 4 e no máximo 9 questionários. Os dados em campo foram coletados entre os meses de novembro e dezembro de 2003. Ao todo foram aplicados 64 questionários, dos quais quatro foram abandonados por inconsistência nas informações.

Às alternativas de respostas foram atribuídos valores numéricos, e dessa maneira as questões foram sistematizadas, para serem submetidas à análise estatística descritiva. Todos os resultados foram obtidos na forma de porcentagens do total. As perguntas abertas e comentários foram considerados durante a interpretação dos resultados das questões fechadas. Foram, ainda, coletadas sugestões e questionamentos de forma oral e escrita, franqueando-se a palavra a todos os presentes.

Com o intuito de verificar a eficácia na transmissão de informações básicas à população durante as reuniões, foram feitas algumas perguntas cujas respostas foram analisadas em relação a quatro grupos distintos de pessoas, conforme descritos a seguir:

Grupo 1: pessoas que participaram de alguma reunião.

Grupo 2: pessoas que receberam informações posteriores sobre a reunião, por terceiros.

Grupo 3: pessoas que participaram da Audiência Pública.

Grupo 4: pessoas que não participaram de nenhuma reunião ou da Audiência Pública, e também não se inteiraram por terceiros do que nelas foi tratado.

\section{RESULTADOS E DISCUSSÃO}

De acordo com os resultados dos dados obtidos nos questionários, 80,6\% da população é descendente de poloneses e 13,4\% de italianos. Desse total, 90,7\% praticam a religião católica. O tamanho médio das propriedades é 18,34 hectares. Cerca de 92\% dos entrevistados reside em casa própria, sendo que a maioria recebeu a propriedade por herança. $86 \%$ dos agricultores utilizam alguma prática de conservação do solo, o que preserva a qualidade dos rios e da represa e seu próprio patrimônio. 
A grande maioria dessas unidades de produção é familiar, possuindo apenas uma propriedade. $85 \%$ das lavouras são mecanizadas e há utilização de fertilizantes e agrotóxicos numa parcela significativa dessas propriedades. $56 \%$ das propriedades não investiram nos últimos 3 anos (1999-2002). A maioria, aproximadamente $77 \%$, não possui financiamento junto a instituições financeiras. $83 \%$ dos produtores são independentes, isto é, não se ligam a nenhum sistema cooperativo ou associativo. Boa parte da população, aproximadamente $84 \%$ dos habitantes, não estuda. A maioria dos moradores não possui nenhum tipo de assistência particular à saúde. Devido à restrição da abertura de novas áreas agricultáveis, há uma crescente desvinculação dos descendentes com a propriedade rural. A população não verifica grandes desmatamentos ou grande supressão de vegetação ou incêndios que tenham prejudicado a vegetação nos últimos 5 anos.

As demais perguntas tiveram como objetivo verificar se existe o conhecimento básico do objetofoco das reuniões, que é justamente o termo que o define. Pode-se afirmar que as respostas positivas não se destacam em nenhum grupo, indicando que não há diferença sobre o conhecimento do termo "Área de Proteção Ambiental" entre as pessoas que participaram ou não de alguma reunião. Isso pode se justificar pelo fato de as pessoas confundirem o termo área de proteção ambiental com reserva legal ou área de preservação permanente. No entanto, nota-se que as respostas negativas concentram-se no Grupo 4, indicando que a maioria das pessoas que desconhece o termo área de proteção ambiental está entre aquelas que não participaram de nenhuma reunião e nem delas tomou conhecimento posterior.

Constata-se que o termo $A P A$ é mais conhecido entre as pessoas que participaram de alguma reunião ou da audiência pública. Esse conhecimento cai à metade entre os que receberam informações por terceiros, indicando que o termo $A P A$ não foi reproduzido pelos informantes com a mesma ênfase das reuniões. As respostas negativas, no entanto, a exemplo da pergunta anterior, concentram-se no Grupo 4. Observou-se que a maior incidência de respostas positivas para a questão "Você sabe o que é uma APA?" se encontra entre os grupos que participaram de alguma reunião ou da audiência pública. Mas, mesmo nesses grupos, é elevado o índice de respostas negativas. Isso indica que nas reuniões foi explicado o que é uma APA, mas essa explicação não atingiu a todos de forma homogênea. Nas reuniões e na audiência pública, aproximadamente a metade das pessoas entendeu e conseguiu reproduzir a informação, mas a outra metade não conseguiu fazê-lo.

No que se refere às razões que levam à criação de uma APA, inicialmente as alternativas de respostas foram: promover o bem-estar humano e ecológico (resposta esperada); promover bem-estar somente ecológico; outros; não sei. Ressalta-se que a alternativa "proteger a água" não foi inicialmente colocada no questionário. Tal resposta, quando aparecia, era colocada como “Outros”. Mas a freqüência com que foi dada justificou abrir uma alternativa separada para ela.

Observou-se que, para as pessoas que participaram de alguma reunião (Grupos 1 e 3), proteger a água é a principal razão pela qual se cria uma Área de Proteção Ambiental. Isso denota uma tendência das reuniões, também detectada nos registros, de enfocar que a APA foi criada para proteger a água da bacia do Rio Verde para o abastecimento público de municípios vizinhos, especialmente Curitiba. Tal enfoque levou a interpretações distorcidas por parte da comunidade. Tais interpretações são externalizadas com comentários do tipo: "Se a água do Rio Verde é boa, por que não podemos mais plantar usando agrotóxicos, como sempre fizemos?". Ou: "Antes não tivéssemos cuidado de nossa propriedade e da água, assim não vinham nos incomodar agora”. O Grupo 4, que não participou das reuniões, não demonstra essa tendência, pelo contrário, com respostas bem diversificadas, a questão da água foi a menos citada, sendo que a resposta esperada, bem estar humano e ecológico, é mais citada nesse grupo.

$\mathrm{O}$ conhecimento de que moram numa área de proteção ambiental é maior entre as pessoas que participaram de pelo menos uma reunião ou da audiência pública (Grupos 1 e 3) que para aquelas que não participaram. Dentre as pessoas que participaram de alguma reunião, a cada 3, 2 responderam conhecer que moram numa área de proteção ambiental, e dentre as que participaram da audiência pública, a cada 4, 3 responderam afirmativamente. Sobre a questão "Você sabe quando foi criada a área de proteção ambiental do Rio Verde?", a alternativa "Este ano" foi incluída para captar a idéia de que as pessoas vinculam a criação da APA com a realização das reuniões. A alternativa "Há dez anos" foi incluída para captar a idéia de que as pessoas vinculam a criação da APA com a criação da represa da Petrobrás, criada há mais de dez anos no Rio Verde.

Observa-se que essas confusões são muito mais freqüentes no Grupo 4, ou seja, entre as pessoas que não participaram de nenhuma reunião. Nesse grupo ainda, a resposta certa, "Há três anos", é bem 
menos freqüente. Isso evidencia que as reuniões ou a audiência pública, ou ambas, foram esclarecedoras no aspecto de situar a comunidade dentro de um contexto histórico e geográfico em relação à APA.

A expressão "Macrozoneamento Ecológico-Econômico" da APA do Rio Verde foi amplamente utilizada no processo de participação popular, uma vez que era o próprio objeto a ser discutido. As pessoas que participaram de alguma reunião ou da audiência pública, ou que tomaram conhecimento por terceiros do assunto tratado nas reuniões declararam ter ouvido falar no termo, com uma freqüência bem maior do que as que não participaram. No entanto, o conhecimento sobre o significado exato do termo não teve essa mesma distinção. Em números absolutos, apenas uma pessoa soube responder corretamente o significado da expressão "Macrozoneamento Ecológico-Econômico", e essa única pessoa encontra-se no Grupo 1, representando $100 \%$ das respostas positivas.

O principal ponto de conflito para a implementação do Macrozoneamento da APA do Rio Verde é o impacto que possa causar para a economia da região. Os moradores estão apreensivos com as propostas de mudança nos padrões de produção agrícola ora vigentes, com o qual estão acostumados. É difícil para eles entender, aceitar e implementar as mudanças necessárias, sobretudo quando essas mudanças passam por adaptações de ordem econômica, exigindo investimentos que os agricultores familiares da APA visivelmente não podem fazer com recursos próprios. Sendo assim, é natural se esperar questionamentos a esse respeito. Com a expectativa de captar as possíveis alternativas apresentadas a esses agricultores, foram incluídas no questionário as seguintes perguntas: "O senhor tem conhecimento de algum recurso financeiro que virá ao município em função da criação da APA do Rio Verde? Você já ouviu falar em ICMS Ecológico?". As respostas chamam a atenção para a Audiência Pública. Nesta, parece ter-se falado mais a respeito que nas reuniões e nas conversas paralelas. Nas reuniões, parece ter-se falado de ICMS Ecológico, mas sem se esclarecer que é um recurso financeiro que o município receberá após implantação da APA, e que deve ser usado para cumprir os seus (LOUREIRO, 2002).

Conforme a tabela 2 , aproximadamente $62 \%$ do universo pesquisado consideraram que as reuniões não foram esclarecedoras. $66,7 \%$ das pessoas com ensino primário e $33 \%$ das pessoas com nível superior consideraram não-esclarecedoras. Ao que tudo indica, o modo de explanação foi mais direcionado para pessoas com nível mais elevado de instrução, e as dúvidas das pessoas menos instruídas, que são aquelas que têm sua renda advinda totalmente da produção agrícola, não foram sanadas. $O$ fato de receber ou não assistência técnica não mostrou distinção no grau de compreensão das pessoas. $\mathrm{O}$ fato de pertencer a uma entidade de classe mostrou uma ligeira tendência a uma melhor compreensão dos assuntos tratados na reunião.

Tabela 2. Perfil geral da população em relação às perguntas-filtro.

Table 2. General profile of the population in relation to the filter questions.

\begin{tabular}{cc}
\hline & Valores em \% \\
\hline Escolaridade & 100 \\
Ensino médio ou superior & 17 \\
Ensino fundamental $\left(1^{\text {a }}\right.$ a $8^{\text {a }}$ séries $)$ & 83 \\
Assistência técnica & 100 \\
Recebe & 13 \\
Não recebe & 87 \\
Entidade de classe & 100 \\
Pertence & 26 \\
Não pertence & 74 \\
Fontes de renda & 100 \\
Totalmente agrícola & 38 \\
Parcialmente agrícola & 40 \\
Não agrícola & 22 \\
\hline Dados da pesquisa de campo &
\end{tabular}

Cerca de $28,6 \%$ das pessoas que pertencem a alguma entidade de classe afirmaram terem sido esclarecedoras as reuniões, enquanto apenas $14,3 \%$ das pessoas que não pertencem afirmaram terem sua 
dúvidas esclarecidas nas reuniões. O fato de pertencer a uma entidade de classe leva ao exercício de discutir, indagar, deliberar e decidir em conjunto, que não exercita quem não pertence.

A fonte de renda teve grande influência sobre o fato de se sentir ou não esclarecido pelas reuniões. Observou-se que a maior parte $(81,8 \%)$ da população que depende exclusivamente de sua atividade agrícola considerou a reunião não-esclarecedora. Dentre os que dependem parcialmente da atividade agrícola, $50 \%$ afirmaram não terem sido esclarecidos pelas reuniões, e esse número cai a zero entre aqueles que não dependem de atividade agrícola para viver. Isso pode ser explicado pelos muitos detalhes envolvidos na conversão das práticas agrícolas doravante necessárias na região. Quem não depende da atividade agrícola não se preocupa com esses detalhes, mas quem depende exclusivamente da atividade agrícola saiu com muitas dúvidas e questionamentos, pois tais questões lhes afetam diretamente, inclusive na sobrevivência própria e da família.

Do total de homens que participou das reuniões, $68,8 \%$ não se sentiram esclarecidos, e do total de mulheres, $40 \%$ não se sentiram esclarecidas. Isso pode denotar o maior envolvimento dos homens na economia local ou a maior desconfiança e resistência a mudanças, exigindo muitos esclarecimentos e garantias para aceitar uma idéia nova.

Com relação à área média das propriedades, os proprietários de maiores extensões sentiram-se menos esclarecidos, em relação aos de menores extensões. Esse fato está estreitamente ligado à fonte de renda. O tamanho médio das propriedades cujos proprietários possuem renda exclusivamente advinda da produção agrícola é de 27,77 ha. O tamanho médio das propriedades cujos proprietários possuem renda parcialmente advinda da produção agrícola é de 7,39 ha. O tamanho médio das propriedades cujos proprietários não possuem renda advinda da produção agrícola é de 0,135 ha. Portanto, os proprietários das maiores extensões de terra são os que dependem totalmente da produção agrícola para sua sobrevivência e foram aqueles que saíram das reuniões com mais dúvidas e questionamentos não esclarecidos.

\section{CONCLUSÕES}

De acordo com os resultados obtidos, e à luz do referencial teórico, pode-se concluir que:

- As reuniões ou a audiência pública, ou ambas, foram esclarecedoras no aspecto de situar a comunidade dentro de um contexto histórico e geográfico em relação à APA. As pessoas que participaram de tais reuniões, visivelmente em oposição àquelas que não participaram, externaram o conhecimento de que moram em uma área de proteção ambiental e que esta foi criada em 2000.

- A clareza das reuniões não atingiu a todas as pessoas de forma homogênea. Pessoas com baixa escolaridade, com renda totalmente agrícola, se mostraram menos esclarecidas pelas reuniões. Como esse é o perfil da maior parte dos moradores da APA, as reuniões foram pouco esclarecedoras para a maioria dos participantes.

- Dentre os que responderam ter ido à audiência pública para emitir sua opinião, todas possuem nível superior de escolaridade, demonstrando que pessoas com baixo nível de escolaridade estão pouco ou nada acostumadas a falar em eventos populares, e menos ainda a serem ouvidas.

\section{REFERÊNCIAS}

BORDENAVE, J. D. O que é participação. São Paulo: Brasiliense, 1983. 84 p.

BRANDENBURG, A. Agricultura familiar: ONGs e desenvolvimento sustentável. Curitiba: Editora da UFPR, 1999. $326 \mathrm{p}$.

BRASIL. Lei $\mathrm{n}^{\circ} 9985$, de 18 de julho de 2000 . Regulamenta o art. 225 , $\S 1^{\circ}$, incisos I, II, II e VII da Constituição Federal, institui o Sistema Nacional de Unidades de Conservação da Natureza e dá outras providências. Diário Oficial da República Federativa do Brasil. Brasília, DF, 19 de julho de 2000.

COORDENAÇÃO DA REGIÃO METROPOLITANA DE CURITIBA (COMEC). Macrozoneamento ecológico-econômico da APA do Rio Verde. Curitiba, 2002. 
DIETZ, L. A.; TAMAIO, I. Aprenda fazendo: apoio aos processos de Educação Ambiental. Brasília, DF: WWF Brasil, 2000. 385 p.

DRAPER, N. R.; SMITH, H. Apllied regression analysis. New York: J. Willy \& Sons, 1981.

GÜNDING, L. Public Participation in enviroment decision-making: trends in environmental olicy and law. Suíça: Gland, 1980.

LEFF, E. Ecologia, capital e cultura: racionalidade ambiental, democracia participativa e desenvolvimento sustentável. Blumenau: Ed. da FURB, 2000.

LOUREIRO, W. Contribuição do ICMS Ecológico à conservação da biodiversidade no Estado do Paraná. 189 f. Tese. (Doutorado em Ciências Florestais) - Setor de Ciências Agrárias, Universidade Federal do Paraná, Curitiba, 2002.

MILDER, L. Análise do processo de construção participativa para elaboração do macrozoneamento ecológico econômico da Área de Proteção Ambiental Estadual do Rio Verde - Pr. Dissertação (Mestrado em Ciências Florestais) - Setor de Ciências Agrárias, Universidade Federal do Paraná, Curitiba, 2004.

PARANÁ. Decreto n ${ }^{\circ} 2375 / 00$ de 28 de julho de 2000. Institui a Área de Proteção Ambiental do Rio Verde, denominada APA do Rio Verde, localizada nos municípios de Araucária e Campo Largo, Estado do Paraná. Diário Oficial, n. 5795 de 31/07/2000. Disponível em: $<$ http://www.pr.gov.br/casacivil/legislação.shtml>. Acesso em: 17/06/05.

SOUZA, M. L. Desenvolvimento de comunidade e participação. São Paulo: Cortez, 1987. 231 p. 